\title{
Recomendações para o design de imagens audiotáteis impressas em 3D com foco na educação inclusiva de cegos
}

\author{
Recommendations for the design of $3 D$ audio-tactile graphics with the focus \\ on inclusive education for the blind
}

\author{
Emilia Christie Picelli Sanches, Juliana Bueno, Maria Lucia Leite Ribeiro Okimoto
}

imagens audiotáteis, cegueira, educação inclusiva, design da informação

O design da informação tem como foco a seleção, arranjo e apresentação de informações em um determinado ambiente e suporte, para que sejam compreendidas pelas pessoas de forma eficiente, eficaz e significativa. Ainda que o design da informação trabalhe em grande parte com informações visuais, outros sentidos também podem ser explorados (ou mesmo serem necessários) para que a mensagem chegue ao receptor final, como é o caso de estudantes cegos, que utilizam o tato e a audição para compreender informações. Um dos materiais possíveis de serem utilizados para a educação de cegos é a imagem audiotátil, onde a superfície tátil possui pontos associados com explicações e/ou descrições em áudio. O objetivo deste artigo é apresentar recomendações para o design de imagens audiotáteis impressas em 3D, como foco na educação inclusiva. Para isso, a pesquisa passou por pesquisa teórica (Revisão Bibliográfica Sistemática e seus alertas, revisão assistemática) e pesquisa de campo (entrevista com especialistas). Ao final, 62 recomendações foram geradas.

Audio-tactile graphics, blindness, inclusive education, information design

Information design focuses on the selection, arrangement and presentation of information in a given environment and support, so that they are understood by people in an efficient, effective and meaningful way. Although information design works largely with visual information, other senses can also be explored (or even needed) so that the message reaches the final recipient, as is the case with blind students, who use touch and hearing to understand information. One of the possible materials to be used for the education of the blind is the audio-tactile graphics, where the tactile surface has points associated with audio explanations and/or descriptions. The purpose of this paper is to present recommendations for the design of $3 D$ printed audio-tactile graphics, with a focus on inclusive education. To achieve this, the research went through theoretical research (Systematic Literature Review and its alerts, unsystematic review) and field research (interview with experts). At the end, 62 recommendations were generated.

\section{Introdução}

O design da informação, enquanto área de atuação, tem como foco a seleção, arranjo e apresentação de informações (geralmente visuais) em um determinado ambiente e suporte, para que sejam compreendidas pelas pessoas de forma eficiente, eficaz e significativa (Coates \& Ellison, 2014; Portugal, 2010). Para Frascara (2016), o design da informação precisa ser centrado no ser humano, já que faz parte do processo entendê-lo para "atender às suas

Anais do $10^{\circ} \mathrm{CIDI}$ e $10^{\circ} \mathrm{CONGIC}$

Kelli C.A.S. Smythe, Rafael de Castro Andrade (orgs.)

Sociedade Brasileira de Design da Informação - SBDI

Curitiba | Brasil | 2021
Proceedings of the $10^{\text {th }} \mathrm{CIDI}$ and $10^{\text {th }}$ CONGIC

Kelli C.A.S. Smythe, Rafael de Castro Andrade (orgs.)

Sociedade Brasileira de Design da Informação - SBDI Curitiba | Brazil | 2021 
necessidades, possibilidades, limitações, e seus desejos" (Frascara, 2016, p.62, tradução nossa). Assim, ainda que o design da informação trabalhe em grande parte com informações visuais, outros sentidos também podem ser explorados (ou mesmo serem necessários) para que a mensagem chegue ao receptor final.

Este é o caso de pessoas cegas. Quando o receptor da informação é cego, é necessário atender a sua necessidade informacional por canais diferentes do visual, tais como a audição e o tato. O princípio é verdadeiro também em ambientes onde a informação é voltada para a aprendizagem, sendo direito da pessoa com deficiência (dentre estas, as cegas) o acesso a um sistema educacional inclusivo (Brasil, 2015).

Ainda assim, uma das principais barreiras enfrentadas por estudantes cegos é a aprendizagem, seja por falta de materiais ou Tecnologia Assistiva adequada, ou, ainda, por informações imprecisas e má desenvolvidas nos materiais existentes (Garcia \& Souza, 2016; Mendonça et al., 2008).

A acessibilidade informacional e inclusão escolar de pessoas cegas acontece na superação de qualquer barreira que evite o cego de ter o acesso ao mesmo conteúdo, na mesma qualidade. Neste contexto, o design da informação pode contribuir para o design de materiais didáticos voltados aos cegos, levando em consideração as características dos sentidos tátil e auditivo.

Um dos materiais possíveis de serem utilizados para a educação de cegos é a imagem audiotátil, cujo propósito é ser uma imagem acessível por dois canais sensoriais: o tato e a audição. Ele é um material interativo e áudio responsivo (Holloway, Marriott \& Butler, 2018; Kolitsky, 2019; Shi et al., 2019; Thevin et al., 2019), onde a superfície tátil possui pontos associados com explicações e/ou descrições em áudio.

Como vantagens apontadas por pesquisadores em favor do uso das imagens audiotáteis estão: a diminuição do tamanho da imagem (logo, menos uso de material para fabricação, em comparação com imagens somente táteis), já que não é necessária a impressão em Braille; estudantes que não leem em Braille podem se beneficiar (cegos, videntes e outros estudantes com deficiência); as imagens podem ser reconfiguráveis, trocando-se os áudios associados com a superfície tátil (Holloway, Marriott \& Butler, 2018; Thevin et al., 2019).

Assim como as imagens táteis (aquelas que usam somente o tato para prover informações), os processos de fabricação são variados, dentre eles a impressão 3D. Esta tecnologia, que produz a informação tátil da imagem, é aliada a outras que produzem a informação sonora, tais como placas eletrônicas, câmeras ou telas sensiveis ao toque.

Em Revisão Bibliográfica Sistemática (RBS) realizada anteriormente, verificou-se que, dentre as pesquisas que tratavam sobre o tema de imagens audiotáteis impressas em $3 \mathrm{D}$, as que abordavam recomendações, boas práticas ou diretrizes para o projeto destes materiais eram incipientes. Destas, nenhuma tratava o problema a partir do design da informação.

Assim, se iniciou uma pesquisa com o objetivo de gerar um artefato informacional que auxiliasse os projetos de imagens audiotáteis impressas em 3D, com o foco na educação 
inclusiva. A primeira fase da pesquisa consistiu em coletar e compilar uma série de recomendações através de fontes teóricas e pesquisa de campo.

Portanto, o objetivo deste artigo é apresentar estas recomendações organizadas e coletadas de todas as fontes, sendo elas: RBS, atualizações da RBS através de alertas nas bases de dados, revisão assistemática e entrevistas com especialistas.

$\mathrm{O}$ artigo se organiza em:

- Introdução;

- Breve apresentação das imagens audiotáteis, em especial as impressas em 3D;

- Estratégia de execução da pesquisa;

- Apresentação das recomendações para o design de imagens audiotáteis; e

- Considerações finais.

\section{Imagens audiotáteis: breve apresentação}

Imagens audiotáteis são materiais projetados para serem percebidos e compreendidos através de dois canais sensoriais distintos: a audição e o tato. Algumas evidências acadêmicas sobre a utilização desses dois sentidos combinados em um material são datadas da década de 1970, como nos estudos de Slamecka et al. (1972) e Blazie e Cranmer (1976).

Dentro deste universo, existem as imagens audiotáteis que são impressas em 3D. Nas pesquisas de outros autores, também pode ser apresentada como modelo tátil-responsivo ou modelo interativo impresso em 3D (Giraud et al., 2017; Kolitsky, 2019; Rossetti et al., 2018; Shi et al., 2019).

De acordo com Götzelmann (2018, p. 4, tradução nossa), o objetivo de uma imagem audiotátil é "fornecer informações adicionais armazenadas como conteúdo eletrônico a elementos gráficos nos quais o usuário está interessado". Dividir as informações da imagem entre tato e audição auxiliam na diminuição da complexidade tátil (se comparadas a uma imagem tátil com as mesmas informações) e do tamanho final da imagem, já que na imagem audiotátil os elementos gráficos táteis e o Braille não disputam o mesmo espaço (Shi, Zhao \& Azenkot, 2017).

Aliadas à tecnologia de impressão 3D, a imagem audiotátil pode ser desenvolvida com, por exemplo, placas eletrônicas de baixo custo (tais como Arduíno e Raspberry Pi), visão computacional, telas sensíveis ao toque e wearables (Reinder, Butler \& Marriott, 2020; Shi et al., 2019; Davis et al., 2020; D'Agnano et al., 2015).

Quanto ao contexto de aplicação, as evidências apontam para o uso das imagens audiotáteis impressas em 3D majoritariamente como um recurso educacional, mas também podem ser utilizadas como recurso para orientação e mobilidade de cegos ou como materiais para uso em museus e monumentos históricos (Shi et al., 2019; Götzelmann, 2018; Leporini et al., 2020). 


\section{Estratégia de pesquisa}

Para a execução da pesquisa, quatro etapas de coleta de dados foram estruturadas. Em um primeiro momento, uma Revisão Bibliográfica Sistemática (RBS) foi realizada, seguida de uma atualização da revisão a partir de alertas fixados nas bases de dados acadêmicos. Além disso, a revisão assistemática integrou as informações teóricas coletadas. Por fim, cinco entrevistas com especialistas também compuseram a pesquisa, complementando as fontes teóricas. A Figura 1 apresenta a composição da pesquisa em suas etapas simplificadas.

Figura 1: Etapas simplificadas da pesquisa. Fonte: as autoras.

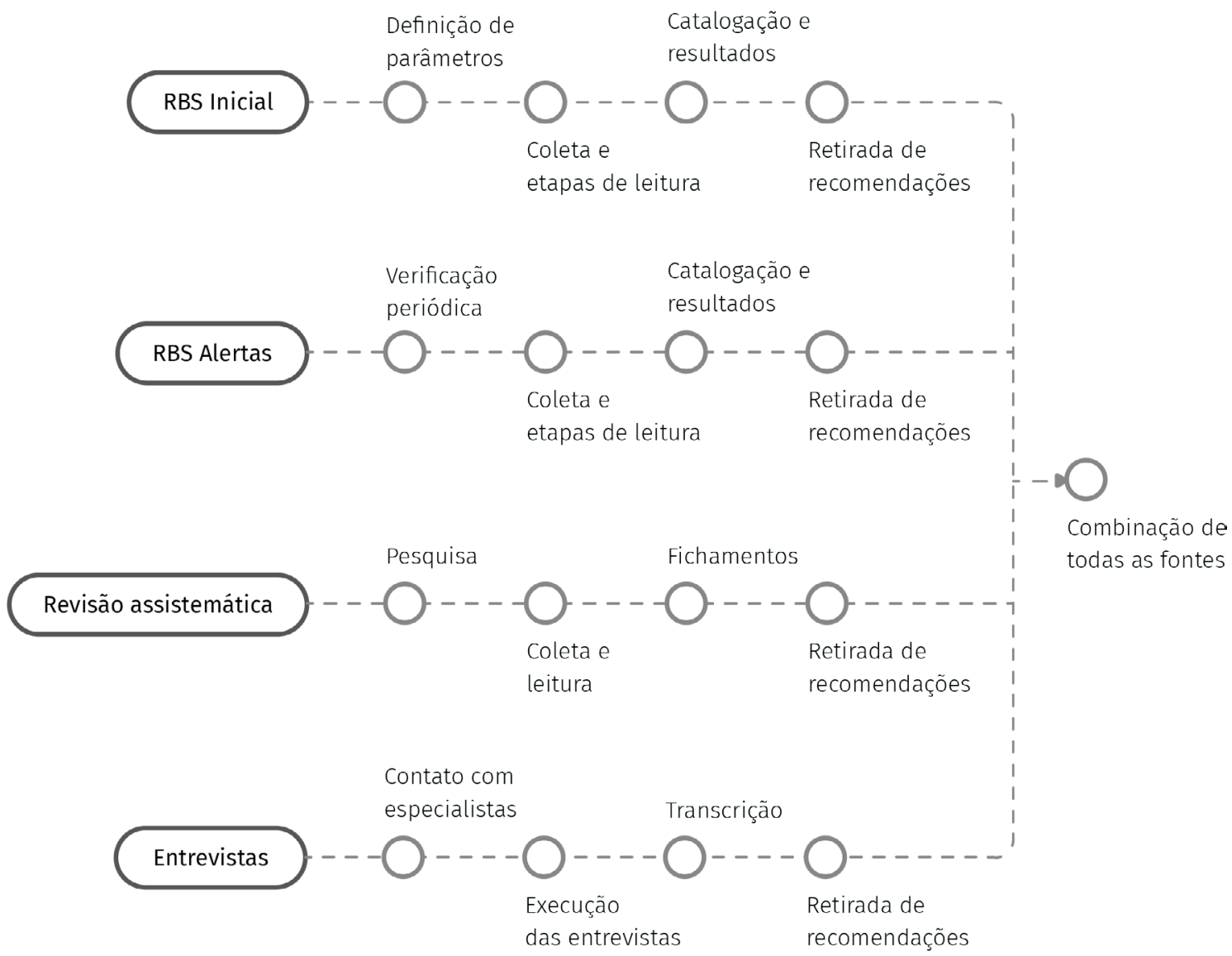

A RBS seguiu critérios de inclusão e exclusão para avaliar cada resultado das bases de dados. Os detalhes sobre os procedimentos e resultados foram publicados em Sanches e Okimoto (2021) e Sanches, Bueno e Okimoto (2021).

Já a revisão assistemática teve por objetivo complementar a RBS, com publicações cujos temas não tratavam de imagens audiotáteis em si, mas eram tangentes - tais como audiodescrição didática e imagens táteis impressas em 3D. Uma lista completa das referências da RBS e da revisão assistemática pode ser conferida neste documento no Google Drive. ${ }^{1}$

\footnotetext{
${ }^{1}$ https://drive.google.com/file/d/1V6c-DH81-LpjsUYFuGEDGHsaCS87IEt5/view?usp=sharing
} 
A partir da coleta de dados, as informações teóricas foram fichadas, enquanto as entrevistas foram transcritas. Em seguida, cada fonte foi tabulada individualmente, retirando-se as recomendações.

\section{Recomendações para o design de imagens audiotáteis impressas em 3D}

Após a execução dos procedimentos da pesquisa - RBS, alertas da RBS, revisão assistemática e entrevistas, as recomendações foram retiradas das publicações acadêmicas e/ou transcrições das entrevistas. Inicialmente, cada fonte foi analisada separadamente. Após a retirada das recomendações, estas foram combinadas para compor um único conjunto.

A Figura 2 apresenta o número de recomendações retiradas de cada fonte e o número final do conjunto de recomendações.

Figura 2: fontes que compõe o conjunto de recomendações. Fonte: as autoras.

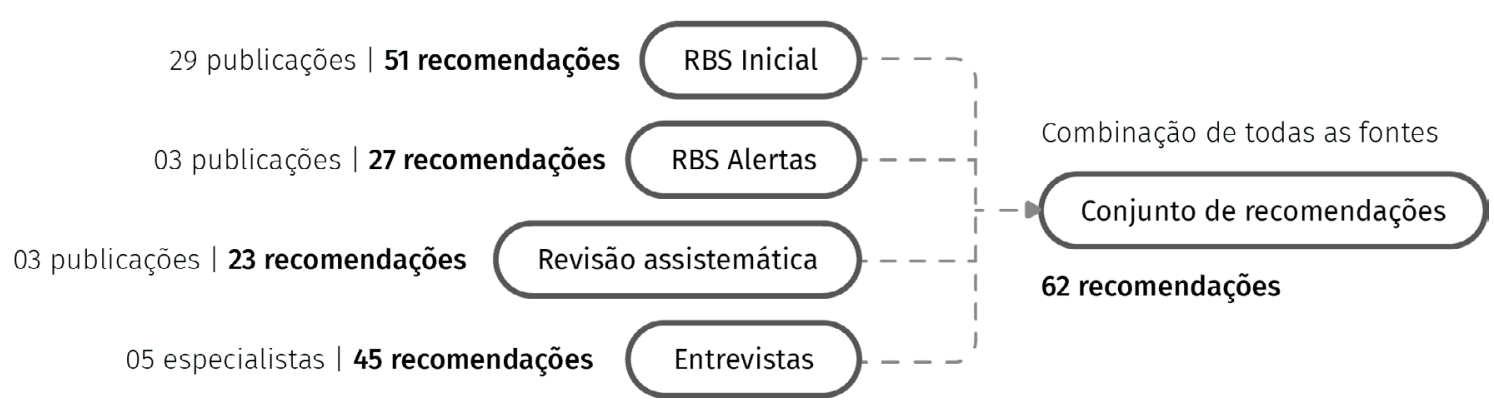

Conforme apresentado, após a combinação de todas as fontes, o conjunto final é consistido de 62 recomendações. Cada recomendação foi escrita a partir da combinação de fontes similares, complementando informações quando era possível. São propostas cinco categorias para o conjunto de recomendações, como forma de organização das informações:

- Contexto e uso;

- Tato;

- Áudio;

- Interação;

- Fabricação.

A seguir são apresentadas todas as recomendações, nas Tabelas 1, 2, 3, 4 e 5, numeradas de 1 a 62 e seguidas de suas fontes. 
Tabela 1: Recomendações da categoria Contexto e uso.

\begin{tabular}{|c|c|c|}
\hline Número & Recomendação & Fonte \\
\hline 1 & $\begin{array}{l}\text { Em caso de um conjunto de imagens audiotáteis sobre o mesmo assunto, } \\
\text { criar também uma única, simplificada, que represente o todo. }\end{array}$ & Assistemática \\
\hline 2 & $\begin{array}{l}\text { Manter a consistência entre diferentes imagens, evitando fazer mudanças } \\
\text { nos termos verbais utilizados, no leiaute, forma e posição dos elementos } \\
\text { táteis, principalmente se forem parte de um mesmo conjunto. Exemplos: } \\
\text { botões sempre na mesma posição, mesma escala. }\end{array}$ & $\begin{array}{l}\text { RBS, Alertas, } \\
\text { Assistemática }\end{array}$ \\
\hline 3 & $\begin{array}{l}\text { Usar métodos faça-você-mesmo (do-it-yourself, DIY), para proporcionar um } \\
\text { conteúdo personalizado. Exemplos: estudantes gravando os próprios áudios, } \\
\text { professores(as) aprendendo e desenvolvendo as próprias impressões 3D. }\end{array}$ & $\begin{array}{l}\text { RBS, } \\
\text { Entrevistas }\end{array}$ \\
\hline 4 & $\begin{array}{l}\text { Explorar o lúdico e o reflexivo em imagens audiotáteis para crianças, } \\
\text { estimulando o engajamento e acesso às representações simbólicas. } \\
\text { Exemplos: tom de voz, cheiros, brincadeiras, peças de encaixar. }\end{array}$ & $\begin{array}{l}\text { RBS, } \\
\text { Entrevistas }\end{array}$ \\
\hline 5 & $\begin{array}{l}\text { Prezar pela qualidade estética visual, auditiva e tátil, pois é benéfico para a } \\
\text { inclusão social e cultural de crianças cegas. }\end{array}$ & RBS, Alertas \\
\hline 6 & As imagens audiotáteis precisam ser portáteis. & RBS \\
\hline 7 & $\begin{array}{l}\text { Ter um(a) educador(a) ou tutor(a) para auxiliar o estudante cego, } \\
\text { contextualizando o conteúdo e tirando dúvidas sobre o uso da imagem } \\
\text { audiotátil. }\end{array}$ & $\begin{array}{l}\text { RBS, } \\
\text { Entrevistas }\end{array}$ \\
\hline 8 & $\begin{array}{l}\text { As informações táteis e sonoras são complementares entre si, entretanto, } \\
\text { se dá maior ênfase à informação tátil. O tátil pode melhor representar } \\
\text { informações espaciais - dimensão, forma, volumetria, texturas; e o áudio } \\
\text { pode melhor retratar descrições - cores, expressões faciais, aspectos } \\
\text { históricos, sonoplastia, exemplos de formas similares, ou outras } \\
\text { informações onde relações espaciais não sejam importantes. }\end{array}$ & $\begin{array}{l}\text { Alertas, } \\
\text { Entrevistas }\end{array}$ \\
\hline 9 & $\begin{array}{l}\text { Ao planejar o conteúdo, priorizar o desenvolvimento de materiais que não } \\
\text { são facilmente encontrados em 3D, são inacessíveis (arquitetura ou objetos } \\
\text { grandes, por exemplo), ou que são pouco abordados no currículo } \\
\text { (historicamente, mulheres ou pessoas negras, por exemplo). }\end{array}$ & Entrevistas \\
\hline 10 & $\begin{array}{l}\text { Substituir toda ou a maior parte das informações em Braille por gravações em } \\
\text { áudio. Braille pode ser utilizado para pequenas marcações ou como recurso } \\
\text { extra. Exemplos: títulos, indicação de onde começar a exploração tátil. }\end{array}$ & $\begin{array}{l}\text { RBS, Alertas, } \\
\text { Entrevistas }\end{array}$ \\
\hline 11 & $\begin{array}{l}\text { Envolver indivíduos com deficiência visual (cegos, baixa visão) e } \\
\text { educadores no processo de desenvolvimento de imagens audiotáteis (seja } \\
\text { como usuários, testadores, consultores, informantes ou colaboradores). } \\
\text { Exemplos de técnicas: observações, entrevistas, diários, prototipagem } \\
\text { colaborativa, co-design. }\end{array}$ & $\begin{array}{l}\text { RBS, } \\
\text { Entrevistas }\end{array}$ \\
\hline 12 & $\begin{array}{l}\text { Oferecer materiais que garantam acessibilidade a todos os conteúdos } \\
\text { trabalhados em sala de aula, de forma equivalente aos dos colegas } \\
\text { videntes, sem acrescentar carga cognitiva extra. Além disso, oferecer } \\
\text { possibilidades de participação plena no compartilhamento de conhecimento } \\
\text { com o seu grupo. Para isso, os materiais acessíveis, imagens audiotáteis } \\
\text { ou não, devem estar prontos antes do início das atividades/aulas. }\end{array}$ & $\begin{array}{l}\text { Assistemática, } \\
\text { Entrevistas }\end{array}$ \\
\hline 13 & $\begin{array}{l}\text { Ao planejar uma imagem audiotátil, selecionar quais são os elementos } \\
\text { principais para que o conceito seja compreendido. }\end{array}$ & Entrevistas \\
\hline
\end{tabular}


14 Começar o ensino com uma imagem simplificada, aumentando o nível de

Entrevistas detalhamento conforme o desenvolvimento do estudante ou, ainda, ensinar por partes, por exemplo, só a cabeça, depois as orelhas, depois os olhos, etc., finalizando com uma imagem do conteúdo completo. visão. Exemplo: pode-se fazer descrição e uso de cores, é significativo para pessoas cegas e ainda inclui pessoas com baixa visão e videntes.

RBS,

Assistemática, Entrevistas

RBS, Alertas, Entrevistas

RBS, Entrevistas contextos, ou de acordo com os objetivos pedagógicos, bastando trocar os áudios em cada ponto de interação tátil. estudante cego. servem de base para a criação de novos conhecimentos. Os estudantes cegos, por exemplo, trazem suas experiências a partir da não visão.

\section{Alertas}

Assistemática

Tabela 2: Recomendações da categoria Tato.

\begin{tabular}{|c|c|c|}
\hline Número & Recomendação & Fonte \\
\hline 20 & $\begin{array}{l}\text { Explorar diferentes elementos táteis para acomodar as necessidades do } \\
\text { estudante cego (pontos, símbolos, formas geométricas, linhas, linhas } \\
\text { tracejadas, flechas, áreas, texturas, norte geográfico, referências espaciais), } \\
\text { mas priorizar símbolos 3D icônicos ou já bem estabelecidos. Quando for } \\
\text { preciso diferenciar o mesmo elemento tátil (exemplo, dois círculos com } \\
\text { significados diferentes), usar tamanhos diferentes. Levar em consideração } \\
\text { que todos os pontos devem ter tamanho, elevação e espaço compatíveis } \\
\text { para serem explorados e alcançados pelos dedos, exceto para objetos que } \\
\text { tenham orifícios originalmente (exemplo, boca). }\end{array}$ & $\begin{array}{l}\text { RBS, Alertas, } \\
\text { Assistemática, } \\
\text { Entrevistas }\end{array}$ \\
\hline 21 & $\begin{array}{l}\text { A informação tátil deve ser simples, clara e saliente, sem informações } \\
\text { redundantes ou detalhes exagerados que possam confundir o usuário cego. }\end{array}$ & RBS \\
\hline 22 & $\begin{array}{l}\text { Imagens audiotáteis podem variar desde apenas relevo até completamente } \\
\text { tridimensionais (3D). Podem ser modeladas em estilos diferentes, por } \\
\text { exemplo, quebra-cabeça, globo, com uma base fixa, etc. Entretanto, dar mais } \\
\text { ênfase em gerar materiais/objetos tridimensionais e mais próximos ao real. }\end{array}$ & $\begin{array}{l}\text { RBS, Alertas, } \\
\text { Assistemática, } \\
\text { Entrevistas }\end{array}$ \\
\hline 23 & $\begin{array}{l}\text { Não fazer imagens audiotáteis que sejam uma representação em } \\
\text { perspectiva, nem com sobreposições. Se a referência visual (imagem } \\
\text { estática) estiver em perspectiva, a imagem audiotátil deve ser modelada } \\
\text { com vista frontal e/ou lateral. }\end{array}$ & $\begin{array}{l}\text { Assistemática, } \\
\text { Entrevistas }\end{array}$ \\
\hline 24 & $\begin{array}{l}\text { O tamanho da imagem audiotátil varia de acordo com o conteúdo (em } \\
\text { média, } 280 \times 290 \mathrm{~mm} \text { ), porém, imagens muito grandes ou muito pequenas } \\
\text { dificultam o aprendizado. Por isso, evitar imagens menores que a falange } \\
\text { do dedo ou que ultrapassem ao alcance dos braços. Também atentar para } \\
\text { o tamanho padrão da letra Braille. Ao invés de padronizar um tamanho } \\
\text { específico, considerar trabalhar com escalas, trazendo comparações e } \\
\text { contexto entre imagens e objetos diferentes. }\end{array}$ & $\begin{array}{l}\text { Alertas, } \\
\text { Assistemática, } \\
\text { Entrevistas }\end{array}$ \\
\hline
\end{tabular}


25
O estudante deve identificar a imagem audiotátil na sua posição correta, seja nas mãos ou na mesa, e encontrar um ponto de partida para a exploração tátil.

Pequenos detalhes e decorações (do objeto real ou imagem de referência visual) devem ser eliminados ou simplificados na construção dos elementos táteis. Se necessário, fazer uma imagem audiotátil separada em maior escala para mostrar esses detalhes. A simplificação não deve descaracterizar o objeto representado, devendo-se manter características que remetam ao objeto real, em um balanço entre simplificação e detalhes.
Entrevistas

RBS, Alertas,

Assistemática, Entrevistas

Tabela 3: Recomendações da categoria Áudio.

\begin{tabular}{|c|c|c|}
\hline Número & Recomendação & Fonte \\
\hline 27 & $\begin{array}{l}\text { Usar palavras do cotidiano, mas não deixar de usar termos corretos e } \\
\text { linguagem técnica adequada. Em caso de dificuldade de transmitir a } \\
\text { informação, pedir ajuda da própria pessoa cega. }\end{array}$ & $\begin{array}{l}\text { Assistemática, } \\
\text { Entrevistas }\end{array}$ \\
\hline 28 & $\begin{array}{l}\text { Incentivar outras crianças a ajudarem na descrição verbal. É muito } \\
\text { enriquecedora a experiência da criança sem deficiência conhecer e usar } \\
\text { este recurso de forma espontânea com seu colega com deficiência visual. } \\
\text { Isto lhes dará melhor percepção do seu entorno, auxiliará em sua } \\
\text { capacidade de concentração e motivará a cooperação. }\end{array}$ & Assistemática \\
\hline 29 & $\begin{array}{l}\text { Descrever uma imagem que contenha apelo emocional de tal forma que } \\
\text { provoque o mesmo impacto à pessoa cega que a imagem provoca ao olhar } \\
\text { de quem enxerga. Na audiodescrição, pode-se passar emoções diferentes } \\
\text { (tristeza, alegria, austeridade, etc.), por exemplo, através do tom da voz ou } \\
\text { tratamento de áudio posterior. }\end{array}$ & $\begin{array}{l}\text { Assistemática, } \\
\text { Entrevistas }\end{array}$ \\
\hline 30 & $\begin{array}{l}\text { Considerar que não há linguagem neutra, nem tradução sem intermediação. } \\
\text { Estar ciente de que suas subjetividades estão presentes no material } \\
\text { oferecido e cuidar para que o direito à interpretação do conteúdo visual seja } \\
\text { dos estudantes. }\end{array}$ & Assistemática \\
\hline 31 & $\begin{array}{l}\text { Os recursos sonoros não são somente verbais. Fazer uso de música e } \\
\text { outro sons não-verbais. Exemplos: som indicando erro ou acerto, sons } \\
\text { lúdicos, sons ambientes, efeitos de som, sons de animais. }\end{array}$ & RBS \\
\hline 32 & $\begin{array}{l}\text { Comentários em áudio podem ser adicionados para contextualizar o } \\
\text { estudante cego. Exemplos: para posicionar a câmera no local correto, para } \\
\text { instruir no uso da imagem, exemplificar comandos, posicionar a imagem no } \\
\text { local correto, prover um contexto geral, etc. }\end{array}$ & RBS \\
\hline 33 & $\begin{array}{l}\text { Evitar sobrecarga de informação sonora de uma só vez. Ao invés de um } \\
\text { áudio longo, gravar várias faixas de áudio curtas, sem passar de dois } \\
\text { minutos cada. Deve-se selecionar quais são as informações mais } \\
\text { relevantes sobre o elemento que se descreve. As informações por áudio } \\
\text { podem explorar níveis de complexidade ou tipo de informação, de acordo } \\
\text { com o gesto aplicado ou botão pressionado (por exemplo, um toque: nome } \\
\text { do elemento; dois toques: explicação breve; comando de voz: informação } \\
\text { mais detalhada). }\end{array}$ & $\begin{array}{l}\text { RBS, Alertas, } \\
\text { Entrevistas }\end{array}$ \\
\hline 34 & $\begin{array}{l}\text { Fazer a descrição verbal de maneira simples, concisa e objetiva, buscando } \\
\text { oferecer o máximo de informação, respeitando o momento de } \\
\text { desenvolvimento de cada estudante e seu potencial de compreensão. }\end{array}$ & $\begin{array}{l}\text { RBS, } \\
\text { Assistemática, } \\
\text { Entrevistas }\end{array}$ \\
\hline
\end{tabular}


Adequar o trabalho ao seu perfil específico, com base em seus conhecimentos anteriores, seu contexto cultural e seu potencial de aprendizagem (inclusive informações em outras línguas, se necessário). Não suprimir informações nem subestimar a capacidade de compreensão do estudante cego.

Tabela 4: Recomendações da categoria Interação.

\begin{tabular}{|c|c|c|}
\hline Número & Recomendação & Fonte \\
\hline 35 & $\begin{array}{l}\text { A interação deve permitir que o estudante cego tenha controle da } \\
\text { informação. Ou seja, permitir que o estudante possa ligar e desligar, repetir, } \\
\text { avançar ou voltar o áudio (para gravações pequenas, pode-se suprimir essa } \\
\text { função), ajustar a velocidade e o volume do áudio. }\end{array}$ & $\begin{array}{l}\text { RBS, Alertas, } \\
\text { Entrevistas }\end{array}$ \\
\hline 36 & $\begin{array}{l}\text { Usar peças tangíveis móveis para aumentar a interação da pessoa cega } \\
\text { com a imagem audiotátil. }\end{array}$ & $\begin{array}{l}\text { RBS, Alertas, } \\
\text { Entrevistas }\end{array}$ \\
\hline 37 & $\begin{array}{l}\text { Inserir marcadores (facilmente detectáveis) para indicar pontos onde há } \\
\text { respostas em áudio. Devem ser projetados para que não sejam confundidos } \\
\text { com elementos táteis da imagem. Esses pontos não devem alterar nem } \\
\text { distorcer significativamente a superfície tátil. }\end{array}$ & RBS \\
\hline 38 & $\begin{array}{l}\text { Levar em consideração que a hierarquia de interação da imagem audiotátil } \\
\text { segue: (1) exploração tátil; (2) gestos táteis para ouvir áudios; (3) comando } \\
\text { de voz para ouvir informações adicionais ou confirmar o entendimento. }\end{array}$ & Alertas \\
\hline 39 & $\begin{array}{l}\text { Para evitar ativações acidentais de áudio pela exploração tátil, incluir uma } \\
\text { ação específica para que o áudio seja liberado (exemplo: pressionar ou } \\
\text { tocar por } 1 \text { segundo para que o áudio comece a tocar). Ativar um áudio } \\
\text { deve ser resultado de uma ação definitiva. }\end{array}$ & RBS \\
\hline 40 & $\begin{array}{l}\text { Além do tato e da audição, outros sentidos podem ser estimulados para } \\
\text { interação extra complementar (olfato, paladar, visão). }\end{array}$ & RBS \\
\hline 41 & $\begin{array}{l}\text { As informações sonoras devem ser fáceis de serem adicionadas ao modelo } \\
\text { tátil, e devem ser intuitivas e fáceis de serem acessadas pelos estudantes } \\
\text { cegos. }\end{array}$ & RBS \\
\hline 42 & $\begin{array}{l}\text { Prover intervenção sonora em caso de erros. Exemplo: peça móvel que foi } \\
\text { encaixada no local errado. }\end{array}$ & Alertas \\
\hline 43 & Permitir que a pessoa cega use as duas mãos para a exploração tátil. & $\begin{array}{l}\text { RBS, } \\
\text { Entrevistas }\end{array}$ \\
\hline 44 & $\begin{array}{l}\text { Fazer uso de gestos táteis/hápticos familiares aos cegos, para ativar } \\
\text { informações sonoras. Podem ser similares aos utilizados em smartphones } \\
\text { ou em gestos naturais da exploração tátil. Exemplos: apontar, bater com o } \\
\text { dedo, escanear com o indicador, escanear com o dedão, beliscar, seguir a } \\
\text { borda com o dedo, fricção com o dedo, um toque, dois toques, três toques, } \\
\text { dois toques com dois dedos, manter toque pressionado, pincelada rápida, } \\
\text { pincelada devagar. }\end{array}$ & $\begin{array}{l}\text { RBS, Alertas, } \\
\text { Entrevistas }\end{array}$ \\
\hline 45 & $\begin{array}{l}\text { Sons acústicos podem ser usados como forma de ativar informações } \\
\text { sonoras. Exemplos: o eletrônico reconhece o som do toque do dedo na } \\
\text { imagem e ativa um áudio, dispositivos acústicos. }\end{array}$ & RBS \\
\hline 46 & $\begin{array}{l}\text { Comando de voz pode ser usado como forma de ativar informações } \\
\text { sonoras. No comando de voz, deve-se implementar uma palavra-chave ou }\end{array}$ & $\begin{array}{l}\text { RBS, Alertas, } \\
\text { Entrevistas }\end{array}$ \\
\hline
\end{tabular}


um botão para ser pressionado que reconhecerá o comando, evitando assim ativações não intencionais. Exemplos: "mais informação", "distância", "o que é isso?", "salvar informação".

47 Botões (em diferentes formatos) podem ser usados como componente RBS, Alertas auxiliar para obter informações por áudio, ou para ter a função ligar/desligar. exploração tátil. Exemplos: (1) Agarrar: segurar a imagem com uma mão e explorar com a outra; (2) Estabilizar: usar uma mão para fixar a imagem na mesa e usar a outra para explorar; (3) Divergir: exploração com as duas mãos em elementos diferentes; (4) Convergir: exploração com as suas mãos em um elemento só. Exemplos: (1) Sentir: sentir as texturas e a forma da imagem; (2) Medir: uso das mãos para medir aproximadamente o tamanho dos elementos táteis; (3) Comparar: comparar dois elementos táteis para conferir se representam o mesmo conceito; (4) Contar: contagem de elementos táteis iguais na imagem; (5) Comunicar: indicar, explicar ou indagar sobre a imagem. $\mathrm{O}$ movimento pode ser para sentir a imagem como um todo ou elementos individualmente.

Tabela 5: Recomendações da categoria Fabricação.

\begin{tabular}{|c|c|c|}
\hline Número & Recomendação & Fonte \\
\hline 50 & $\begin{array}{l}\text { Usar plástico PLA, ABS e/ou resina como materiais de impressão 3D. Além } \\
\text { disso, a impressão 3D pode ser combinada com outros processos de } \\
\text { fabricação digital, como corte a laser, ou mesmo outros materiais (criando } \\
\text { diferentes texturas). Explorar o que funciona melhor no contexto de uso. }\end{array}$ & $\begin{array}{l}\text { RBS, } \\
\text { Entrevistas }\end{array}$ \\
\hline 51 & $\begin{array}{l}\text { A impressão 3D pode ser combinada com eletrônicos de baixo custo. } \\
\text { Exemplos: etiquetas NFC, sensores capacitivos, sensores PIR, placas } \\
\text { Arduíno, placa Touch Board, Raspberry Pi, Makey Makey, Lilypad, sensores } \\
\text { de proximidade. }\end{array}$ & RBS, Alertas \\
\hline 52 & $\begin{array}{l}\text { Manter o processo simples ou prover as ferramentas necessárias para que } \\
\text { mesmo pessoas não especialistas (em impressão 3D e eletrônicos) possam } \\
\text { desenvolver suas próprias imagens audiotáteis. A tecnologia usada deve } \\
\text { ser robusta e de baixo custo, facilitando a capacitação e autonomia dos } \\
\text { educadores. }\end{array}$ & $\begin{array}{l}\text { RBS, Alertas, } \\
\text { Entrevistas }\end{array}$ \\
\hline 53 & $\begin{array}{l}\text { Imagens audiotáteis podem ser desenvolvidas a partir de modificações em } \\
\text { modelos digitais 3D já existentes. Exemplos: encontrados em sites como } \\
\text { Thingiverse, NIH 3D Print Exchange, Nasa 3D Resources, APH Tactile } \\
\text { Image Library, National Lbrary of Medicine Visible Human, globos terrestres. } \\
\text { Ainda, algumas bases de dados podem servir como ferramenta para a } \\
\text { modelagem. Exemplos: OpenStreetMap, Google Place, tactilemap.net, } \\
\text { dados GIS. }\end{array}$ & RBS \\
\hline 54 & $\begin{array}{l}\text { A visão computacional pode ser integrada no desenvolvimento de imagens } \\
\text { audiotáteis. Exemplos: para o reconhecimento de formas, posição do dedo. }\end{array}$ & RBS \\
\hline 55 & $\begin{array}{l}\text { Tablets e smartphones são ferramentas que podem ser integradas no } \\
\text { desenvolvimento de imagens audiotáteis. Exemplos: uso de aplicativos, } \\
\text { tela touch, câmeras, reconhecimento de QR Codes. }\end{array}$ & $\begin{array}{l}\text { RBS, } \\
\text { Entrevistas }\end{array}$ \\
\hline
\end{tabular}


$56 \quad$ O escaneamento 3D é uma maneira de se adquirir modelos fiéis e RBS detalhados do objeto real.

57

Se for necessário utilizar pós-processamento, a impressão 3D não deve ser nem muito áspera nem muito lisa. Deve ser suave ao toque, sem pontas ou bordas afiadas, não inflamável nem nociva, ou seja, a imagem audiotátil deve ser segura para quem manipula.

Levar em consideração as limitações e características da impressora 3D a ser utilizada (por exemplo, tamanho máximo de impressão, material disponível, necessidade de pós-processamento). Se necessário, dividir o modelo digital 3D em diversas partes para serem impressas. Os parâmetros de impressão devem ser ajustados de forma a evitar que imperfeições sejam confundidas com texturas ou componentes da imagem.

59 por áudio ou como forma de integrar um dispositivo eletrônico. Uma alternativa é o uso de tinta condutiva.

Levar em consideração ter entrada para fones de ouvido, para que o estudante cego possa focar na informação. outros educadores, makers, comunidades. De preferência, promover o compartilhamento digital gratuito, público e livre. Exemplo: licenças open source, creative commons, copy left, REA.

Desenvolver um banco de imagens ou elementos táteis normatizados que
RBS,

Assistemática, Entrevistas

RBS, Alertas, Assistemática

RBS,

Entrevistas

RBS,

Entrevistas podem ser usados/reutilizados em diferentes materiais. Exemplo: formas de animais.

Entrevistas

As recomendações aqui apresentadas não são, ainda, consideradas um conjunto finalizado, pois compreende-se que etapas de validação e avaliação do seu conteúdo são necessários. Também se considera benéfica uma reestruturação textual de cada recomendação utilizandose a linguagem simples, com o intuito de deixar as informações diretas, concisas e acessíveis. Entretanto, os resultados já obtidos servem de subsídio para avanço da discussão acadêmica sobre o tema, assim como para outras pesquisas e projetos que visem interligar design da informação com inclusão, em particular àquelas sobre materiais didáticos acessíveis aos estudantes cegos.

\section{Considerações finais}

O design da informação tem o objetivo de organizar informações em um suporte e um ambiente, para que sejam compreendidas de maneira eficaz, eficiente e significativa pelas pessoas. Em um contexto escolar inclusivo, isso significa entregar informações acessíveis, de acordo com as necessidades sensoriais e informacionais dos estudantes com ou sem deficiência. Para estudantes cegos, estrutura-se a informação para que seja compreendida pelos sentidos tátil e auditivo.

Com a premissa de aproximar o design da informação da educação inclusiva, o objetivo deste artigo é apresentar recomendações para o design de imagens audiotáteis impressas em 
3D, para uma educação inclusiva de cegos. A partir da execução das etapas de pesquisa, ou seja, Revisão Bibliográfica Sistemática e seus alertas nas bases de dados, revisão assistemática e entrevistas, foi possível gerar um conjunto de 62 recomendações sobre o tema.

As recomendações aqui apresentadas são consideradas informações com potencial para contribuir com a discussão acadêmica sobre o design de materiais didáticos inclusivos aos cegos, assim como outros projetos que visem interligar design da informação com inclusão.

Ainda assim, compreende-se que as recomendações necessitam passar por etapas de validação e avaliação. Desta forma, os próximos passos previstos para a pesquisa são a reestruturação textual a partir da linguagem simples, execução de Delphi e card sorting.

\section{Referências}

Blazie, D. B., \& Cranmer, T. V. (1976). An audio-tactile display. Behavior Research Methods \& Instrumentation, 8(6), 491-494.

Brasil. (2015). Lei № 13.146, de 6 de julho de 2015. Disponível em http://www.planalto.gov.br/ccivil_03/_ato2015-2018/2015/lei//13146.htm.

Coates, K., \& Ellison, A. (2014). An introduction to information design. London: Laurence King Publishing.

D’Agnano, F., Balletti, C., Guerra, F., \& Vernier, P. (2015). Tooteko: a case study of augmented reality for an accessible cultural heritage. International Archives of the Photogrammetry, Remote Sensing and Spatial Information Sciences, XL-5/W4, 207-213.

Davis, J. U., Wu, T., Shi, B., Lu, H., Panotopoulou, A., Whiting, E., \& Yang, X. (2020) TangibleCircuits: an interactive 3D printed circuit education tool for people with visual impairments. Anais do CHI Conference on Human Factors in Computing Systems, 1-13. https://doi.org/10.1145/3313831.3376513

Frascara, J. (2016). Data, information, design, and traffic injuries. In Oven, P. Č. \& Požar, C. (orgs.). On information design. Liubliana: The Museum of Architecture and Design.

Garcia, F. A., \& Souza, S. R. C. (2016). Intervenções pedagógicas frente às necessidades educacionais especiais no ensino regular. In Nogueira, R. E. Geografia e inclusão escolar: teoria e práticas. Florianópolis: Edições do Bosque/CFH/UFSC.

Giraud, S., Brock, A., Macé, M., \& Jouffrais, C. (2017). Map learning with a 3D printed interactive small-scale model: Improvement of space and text memorization in visually impaired students. Frontiers in Psychology, 8.

Götzelmann, T. (2018). Visually augmented audio-tactile graphics for visually impaired people. ACM Transactions on Accessible Computing, 11(2).

Holloway, L., Marriott, K., \& Butler, M. (2018). Accessible maps for the blind: Comparing 3D printed models with tactile graphics. Anais do CHI Conference on Human Factors in Computing Systems, 1-13. https://doi.org/10.1145/3173574.3173772

Kolitsky, M. (2019). Making 3D laser cut stratigraphic audio-responsive tactile templates. Journal of Science Education for Students with Disabilities, 22(1). 
Leporini, B., Rossetti, V., Furfari., Pelagatti., D., \& Quarta, A. (2020). Design guidelines for an interactive $3 \mathrm{D}$ model as a supporting tool for exploring a cultural site by visually impaired and sighted people. ACM Transactions on Accessible Computing, 13(3), 1-39.

Mendonça, A., Miguel, C., Neves, G., Micaelo, M., \& Reino, V. (2008). Alunos cegos e com baixa visão: orientações curriculares. Lisboa: Ministério da Educação (Portugal).

Portugal, C. (2010). Questões complexas do design da informação e de interação. Revista Brasileira de Design da Informação, 7(2), 1-6.

Reinders, S., Butler., M. \& Marriott, K. (2020). "Hey model!" - natural user interactions and agency in accessible interactive 3D models. Anais do $\mathrm{CHI}$ Conference on Human Factors in Computing Systems, 1-13. https://doi.org/10.1145/3313831.3376145

Rossetti, V., Furfari, F., Leporini, B., Pelagatti, S., \& Quarta, A. (2018). Enabling access to cultural heritage for the visually impaired: an interactive $3 \mathrm{D}$ model of a cultural site. Procedia Computer Science, 130, 383-391.

Sanches, E. C. P., Bueno, J. \& Okimoto, M. L. L. R. (2021). Designing 3D printed audio-tactile graphics: recommendations from prior research. In Antona M. \& Stephanidis C. (eds.). Universal Access in Human-Computer Interaction. Design Methods and User Experience. HCIl 2021. Lecture Notes in Computer Science, vol 12768. Cham: Springer.

Sanches, E. C. P. \& Okimoto, M. L. L. R. (2021). Considerações teóricas sobre imagens audiotáteis impressas em 3D. In Okimoto, M., Paschoarelli, L., Costa, C., Merino, E. \& Foggiatto, J. (orgs.). Tecnologia Assistiva: abordagens teóricas. Bauru: Canal 6.

Shi, L., Lawson, H., Zhang, Z., \& Azenkot, S. (2019). Designing interactive 3D printed models with teachers of the visually impaired. Anais do $\mathrm{CHI}$ Conference on Human Factor in Computing Science, 1-14. https://doi.org/10.1145/3290605.3300427

Shi, L., Zhao, Y., \& Azenkot, S. (2017). Designing interactions for 3D printed models with blind people. Anais do ACM SIGACESS Conference on Computers and Accessibility, 200-209. https://doi.org/10.1145/3132525.3132549

Slamecka, V., Jensen, A. P., Valach, M., \& Zunde, P. (1972). A computer-aided multisensory instruction system for the blind. IEEE Transactions on Biomedical Engineering, BME-19(2), 157-160.

Thevin, L., Jouffrais, C., Rodier, N., Palard, N., Hachet, M., \& Brock, A. (2019). Creating accessible interactive audio-tactile drawings using spatial augmented reality. Anais do ACM International Conference on Interactive Surfaces and Spaces, 17-28. https://doi.org/10.1145/3343055.3359711

\section{Sobre as autoras}

Emilia Christie Picelli Sanches, Mestra, UFPR, Brasil <emilia.ecps@gmail.com> Juliana Bueno, Doutora, UFPR, Brasil <julianabueno.ufpr@gmail.com> Maria Lucia Leite Ribeiro Okimoto, Doutora, UFPR, Brasil <lucia.demec@ufpr.br> 